\title{
The prevalence of infection with head lice pediculus humanus capitis among elementary girl students in Albaha region- Kingdom of Saudi Arabia
}

\section{Fatehia Nasser Gharsan*, Naglaa Fekry Abdel-Hamed, Somia Abd Alla Mohammed Elhassan, Nihad Gubara Abdel Rahman Gubara}

Department of Biology, Albaha University, Saudi Arabia

Received: 20 March 2016

Revised: 24 March 2016

Accepted: 16 April 2016

\author{
*Correspondence: \\ Dr. Fatehia Nasser Gharsan, \\ E-mail: fatehia2002@gmail.com
}

Copyright: () the author(s), publisher and licensee Medip Academy. This is an open-access article distributed under the terms of the Creative Commons Attribution Non-Commercial License, which permits unrestricted non-commercial use, distribution, and reproduction in any medium, provided the original work is properly cited.

\section{ABSTRACT}

Background: Head lice infestation with Pediculus humanus capitis is a widespread health concern among school children. The prevalence of lice infestation and the associated risk factors were assessed among primary school girls in Albaha region.

Methods: A total of 672 girls in Al Makhwa area were examined and interviewed. The prevalence of pediculosis was $45.45 \%$.

Results: The results indicated there was a significant relation between lice infestation and several risk factors: crowdness in classrooms ( $89.52 \%$ in heavily crowded classes); sharing bedrooms $(\mathrm{P} \leq 0.001)$; hair washing frequency and the person washing it $(\mathrm{P} \leq 0.001)$; sharing combs and towels $(69.53$ and $71.4 \%$ respectively); using a hair-dryer $(\mathrm{P} \leq 0.001)$. Girls' school class level, hair characters, family income, number of family members, mother's education and occupation, mode of transport to school and presence of a house servant were found to have no significant impact on head lice infestation.

Conclusions: Family education is needed to implement proper personal hygiene practices and cease sharing personal items. Periodic screening of students at school and home is recommended for early detection and treatment.

Keywords: Medical entomology, Pediculus humanus capitis, Head lice, Prevalence, Risk factors

\section{INTRODUCTION}

Head lice infestation (HLI) caused by Pediculus capitis is a worldwide public health concern that affects mostly school aged children. ${ }^{1}$ HLI does not produce an illness, but it is physically unpleasant and an unbearable social stigma. ${ }^{2}$ Human head lice (Pediculus humanus capitis) have been associated with humans for thousands of years. Transmission occurs by direct contact with an infected person's hair and possibly by sharing combs, hats, and other accessories. The adult louse may remain on bedding or upholstery for a brief time, but viability after being removed from the scalp is less than 2 days. Nits require an ambient temperature similar to that near the human scalp to hatch. ${ }^{3}$

Many factors such as; poor hygiene, socioeconomic status, lack of medical treatment and resistance to the treatment leads to increase the prevalence of head lice. ${ }^{4,5}$ A survey of 2928 primary school girls living in Jeddah, Saudi Arabia, revealed that $(7.9 \%)$ of the girls were infested with Pediculus humans capitis. ${ }^{6}$ 
In Albaha, Saudi Arabia, an infestation rate of $19.8 \%$ was reported among school boys between 9-11 years. ${ }^{7}$ There was a significant difference between infestation rates among the age groups. Personal hygiene practices and socioeconomic status influenced the level of prevalence of pediculosis. ${ }^{8}$ The results of showed that the mean number of family members of the studied population was nine persons living mostly in an apartment of 3-4 rooms. ${ }^{9}$ The prevalence rate was found to be highly influenced by certain factors. These were including the age, the hair characters and crowdness of the classrooms. ${ }^{10}$

Another study in Iran found that children aged 8-9 years showed the highest prevalence rate $(41.7 \%)$ and pupils aged 12 years had the lowest rate of infestation $(3.3 \%)$. The study of showed that (12.2\%) $72 / 590$ of students were infected with Pediculus capitis. ${ }^{11,12}$

In recent years, it was observed that there is an alarming increase in head lice infestation rates amongst primary school girls in Albaha. This has led to complaints from families and school teachers. No similar studies have been carried out in Albaha region so far. This study will aid in identifying the causes and dealing with the significant increase in head lice infestation rates amongst primary school girls in the region.

\section{METHODS}

Assessment of lice prevalence and risk factors among primary school girls: This study was a descriptive, analytical study that was conducted between September 2014 and May 2015. A total of 672 girls from a number of primary schools in Albaha region were examined for infestation with Pediculus humanus capitis (nits, adults, and nymph). After each examination, the students were interviewed during which a data sheet was filled containing the following data: age, school grade hair characters, personal hygiene practices, and crowdness, mode of transport to school and rate or degree of infestation. Hair characters were classified as type (straight, wavy, and curly); color (as fair, brown, and black); length considered as short $(0-3 \mathrm{~cm})$, medium (3$10 \mathrm{~cm})$, and long $(10 \mathrm{~cm})$. Personal hygiene practices include the number of hair washes/week; type of hair oil/cream; sharing comb/brush and towels. The crowdness index of classrooms was calculated as follows:

- $\quad$ Normal = 1 square meter/child

- Crowded $>0.75$ square meter/child

- Heavily crowded $=0.75$ square meter $/$ child. ${ }^{10}$

The crowdness at homes was recorded as the number of children sharing one bedroom; number sharing one bed and previous contact with infected person.

The mode of transport to school was defined as follows: by school bus and the number of students in the bus; by private communal transport with number of girls on board and with family and number of members on board.

The statistical package for the social science (SPSS version 20 for Windows 7) spearman correlation was used.

\section{RESULTS}

\section{Prevalence of lice infestation in schoolgirls according to their class level}

In this study, a total of 672 primary school girls were examined; $45.45 \%$ of the girls were found to be infested with Pediculus humanus. The statistical analysis indicated that there was no significant relation between head louse infestation and class level.

\section{Prevalence of lice infection in schoolgirls according to their hair characters and personal hygiene}

There was no significant correlation in the statistical analysis between hair characters and lice infestation.

The results pertaining to hygiene practices showed that the frequency of hair washing significantly affected lice infestation $(\mathrm{P} \leq 0001)$, where the least head louse infestation was in girls who washed their hair 3 or more times per week $(3.80 \%)$. There was a highly significant correlation between prevalence of lice and the person washing the students' hair $(\mathrm{P} \leq 0.001)$; girls who washed their own hair showed increased infestation (76.19\%) while it was low in those whose mothers were the caretakers $(20.95 \%)$. Sharing a comb was of a very high significant effect $(\mathrm{P} \leq 0.001)$ on the rate of prevalence. Similarly, sharing towels also showed a high significance $(\mathrm{P} \leq 0.001)$. However, using hair oil did not show significance. Blow drying the hair was found to have a strongly significant effect on lice prevalence $(\mathrm{P} \leq 0.001)$. (Table 1).

\section{Prevalence of lice infestation according to the crowdness at school, home and mode of transport to school}

(Table 2) elucidates that crowdness in the classroom was an effective factor on lice prevalence with a significant value of $(\mathrm{P} \leq 0.05)$; the highest infestation was found in heavily crowded classrooms $(89.52 \%)$ which decreased to $10.47 \%$ in normal classrooms. Sharing a bedroom also affected prevalence $(\mathrm{P} \leq 0.05)$. There was a negative correlation between number of persons sharing a single bed and lice infestation $(\mathrm{P} \leq 0.01)$ where the highest rate was found in girls who slept separately in a single bed $(76.19 \%)$.

There was no significant relation between mode of transport and head louse infestation $(\mathrm{P}>0.05)$. 
Table 1: Prevalence of lice infection in school girls according to their hair characters and personal hygiene.

\begin{tabular}{|c|c|c|c|c|}
\hline Hair character & & No. of infested girls & $\%$ of infestation & P value \\
\hline \multirow{3}{*}{ Color } & Black & 59 & 56.19 & \multirow{3}{*}{0.240} \\
\hline & Brown & 40 & 38.09 & \\
\hline & Fair & 6 & 5.71 & \\
\hline \multirow{3}{*}{ Length } & Short & 5 & 4.76 & \multirow{3}{*}{0.495} \\
\hline & Medium & 24 & 22.85 & \\
\hline & Long & 76 & 72.38 & \\
\hline \multirow{3}{*}{ Type } & Straight & 55 & 53.39 & \multirow{3}{*}{0.263} \\
\hline & Wavy & 35 & 33.98 & \\
\hline & Curly & 13 & 12.62 & \\
\hline \multirow{2}{*}{ Kind } & Dry & 41 & 39.04 & \multirow{2}{*}{0.093} \\
\hline & Oily & 64 & 60.95 & \\
\hline \multicolumn{5}{|l|}{ Personal hygiene } \\
\hline \multirow{3}{*}{ No. of hair washes/week } & Once & 95 & 90.47 & \multirow{3}{*}{0.001} \\
\hline & Twice & 6 & 5.71 & \\
\hline & 3 times or more & 4 & 3.80 & \\
\hline \multirow{3}{*}{ Person washing hair } & Student & 80 & 76.19 & \multirow{3}{*}{0.001} \\
\hline & Mother & 22 & 20.95 & \\
\hline & Sister & 3 & 2.85 & \\
\hline \multirow{2}{*}{ Sharing a common comb } & Yes & 73 & 69.53 & \multirow{2}{*}{0.001} \\
\hline & No & 32 & 30.47 & \\
\hline \multirow{2}{*}{ Sharing towels } & Yes & 75 & 71.42 & \multirow{2}{*}{0.001} \\
\hline & No & 30 & 28.57 & \\
\hline \multirow{2}{*}{ Use of hair oil } & Yes & 98 & 93.33 & \multirow{2}{*}{0.276} \\
\hline & No & 7 & 6.67 & \\
\hline \multirow{2}{*}{ Use of hair dryer } & Yes & 28 & 26.67 & \multirow{2}{*}{0.001} \\
\hline & No & 77 & 73.33 & \\
\hline
\end{tabular}

Table 2: Prevalence of lice infestation according to the crowdness at school, home and mode of transport to school.

\begin{tabular}{|c|c|c|c|c|}
\hline \multicolumn{2}{|l|}{ Crowdness } & No. of infested girls & $\%$ of infestation & P value \\
\hline \multirow{3}{*}{$\begin{array}{l}\text { Crowdness in } \\
\text { classroom }\end{array}$} & Normal & 11 & 10.47 & \multirow{3}{*}{0.025} \\
\hline & Crowded & 0 & 0 & \\
\hline & Heavily crowded & 94 & 89.52 & \\
\hline \multirow{5}{*}{$\begin{array}{l}\text { Sharing a } \\
\text { bedroom }\end{array}$} & One person & 15 & 14.28 & \multirow{5}{*}{0.016} \\
\hline & Two & 32 & 30.48 & \\
\hline & Three & 32 & 30.48 & \\
\hline & Four & 22 & 20.96 & \\
\hline & More than four & 4 & 3.80 & \\
\hline \multirow{5}{*}{$\begin{array}{l}\text { Sharing same } \\
\text { bed }\end{array}$} & One person & 80 & 76.19 & \multirow{5}{*}{0.003} \\
\hline & Two & 12 & 11.43 & \\
\hline & Three & 8 & 7.62 & \\
\hline & Four & 3 & 2.85 & \\
\hline & More than four & 2 & 1.91 & \\
\hline \multicolumn{4}{|c|}{ Mode of transport } & \multirow{5}{*}{0.890} \\
\hline \multirow{2}{*}{\multicolumn{2}{|c|}{$\begin{array}{l}\text { School bus } \\
\text { Private transportation }\end{array}$}} & 14 & 13.33 & \\
\hline & & 16 & 15.24 & \\
\hline \multicolumn{2}{|l|}{ W/ family } & 65 & 61.90 & \\
\hline \multicolumn{2}{|l|}{ Walking } & 10 & 9.53 & \\
\hline
\end{tabular}


Table 3: Prevalence of lice infestation according to the socio-economic level.

\begin{tabular}{|c|c|c|c|c|}
\hline Social status & & No. of infested girls & $\%$ of infestation & P value \\
\hline \multirow{3}{*}{ With whom student lives } & Both parents & 103 & 98.0 & \multirow{3}{*}{0.412} \\
\hline & Father only & 0 & 0 & \\
\hline & Mother only & 2 & 2.0 & \\
\hline \multirow{3}{*}{ No. of family members } & $<3$ & 12 & 11.43 & \multirow{3}{*}{0.269} \\
\hline & $4-6$ & 45 & 42.86 & \\
\hline & $\geq 7$ & 48 & 45.71 & \\
\hline \multirow{3}{*}{ Student's order amongst siblings } & Eldest & 21 & 24.70 & \multirow{3}{*}{0.845} \\
\hline & Middle & 50 & 58.83 & \\
\hline & Youngest & 14 & 16.47 & \\
\hline \multicolumn{5}{|l|}{ Educational level } \\
\hline \multirow{3}{*}{ Father's education } & Low & 24 & 29.63 & \multirow{3}{*}{0.006} \\
\hline & Medium & 27 & 33.33 & \\
\hline & High & 30 & 37.04 & \\
\hline \multirow{3}{*}{ Mother's education } & Low & 28 & 34.56 & \multirow{3}{*}{0.218} \\
\hline & Medium & 19 & 23.46 & \\
\hline & High & 34 & 41.98 & \\
\hline \multicolumn{5}{|l|}{ Economic level } \\
\hline \multirow{2}{*}{ Father's job } & Yes & 69 & 85.18 & \multirow{2}{*}{0.033} \\
\hline & No & 12 & 14.82 & \\
\hline \multirow{2}{*}{ Mother's job } & Yes & 37 & 45.67 & \multirow{2}{*}{0.771} \\
\hline & No & 44 & 54.33 & \\
\hline \multirow{3}{*}{ Monthly income } & Low & 9 & 11.12 & \multirow{3}{*}{0.527} \\
\hline & Medium & 36 & 44.44 & \\
\hline & High & 36 & 44.44 & \\
\hline \multirow{2}{*}{ Servant } & Yes & 24 & 22.85 & \multirow{2}{*}{0.116} \\
\hline & No & 81 & 77.15 & \\
\hline
\end{tabular}

Prevalence of lice infestation according to socioeconomic level

\section{Social status}

No significance was found between the number of family members and lice infestation $(\mathrm{P}>0.05)$. Similarly the student's order amongst her siblings was found to be insignificant $(\mathrm{P}>0.05)$.

There was no significant correlation between the mother's educational level and lice infestation $(\mathrm{P}>0.05)$ (Table 3$)$.

\section{Parents' educational level}

The father's education was found to be a strongly significant factor affecting lice prevalence $(\mathrm{P} \leq 0.01)$. There was no significant correlation between the mother's educational level and lice infestation $(\mathrm{P}>0.05)$ (Table 3$)$.

\section{Economic level}

In (Table 3), it was indicated that the father's job had a significant effect on prevalence $(\mathrm{P} \leq 0.05)$. The results also show that infestation was lower in girls with working mothers $(45.67 \%)$ than girls whose mothers were housewives $(54.33 \%)$. This correlation was insignificant $(\mathrm{P}>0.05)$.

The presence of a house servant was insignificant $(\mathrm{P}>0.05)$ as a factor affecting lice prevalence.

\section{DISCUSSION}

Head lice infestations a public health problem common among primary school children. In this study the prevalence rate of infestation among 672 primary school girls was found to be $45.45 \%$. This rate is considerably higher than rates recorded in earlier studies conducted in Saudi Arabia. ${ }^{13}$ Found the prevalence to be $12 \%$ in Jeddah city area, while recorded 7-9\% among primary schoolgirls in the same city. An infestation rate of $19.8 \%$ was reported in Albaha and 5.2\% in Eastern Saudi Arabia. ${ }^{6,7,14}$ More recent studies showed prevalence of $13.3 \%$ in Jazan and $12.2 \%$ among primary school girls in Riyadh city. $^{12,15}$

The higher rate recorded in this study may be due to several reasons mainly that the various studies were conducted over a wide span of years, different seasons, on varying populations and in different climatic regions. 
Furthermore, Albaha region is a rural area, and the rate of lice infestation was recorded to be higher in rural than urban areas by several studies; in Al Hassa by who recorded $49 \%$ and in Jazan by who reported $20.5 \% .^{15,16}$ Other studies also established the same result; in Turkey by (9.7 urban and $20 \%$ rural); in Jordan by (23.5 and $31.2 \%)$; in Iran by $(0.66$ and $1.66 \%)$ and in Yemen by $(20.6 \%)^{17-20}$

The rate of infestation in Egypt was reported as $16.7 \%$ by $26.6 \%$ in Jordan and $13.5 \%$ in Iraq. ${ }^{10,18,21}$ In Turkey the rates ranged from 0.54 to $29.4 \%$ with an average rate of $10.16 \%$ and the rate was found to be $48 \%$ in India among children, Worldwide, in Europe prevalence varied from $0.48 \%$ to $22.4 \%$. It was found to be $3.3 \%$ in France. It was also reported to be $13 \%$ in Australia and $40 \%$ in Taiwan. $^{22-25}$

The prevalence rate of head louse infestation in the present study is similar to that found in Taiwan and India but different and higher than results recorded in the Middle East and other countries worldwide. This increase in prevalence has come to the notice of education and health officials over the past several years and has become an alarming phenomenon in Albaha region. It may be due to the lack of periodic screening programs in schoolchildren, and health awareness programs for families about prevention and early detection. Furthermore, the development of lice resistance to chemical pediculicides may play an important role. ${ }^{27}$

Many studies have recorded significant variations in the rate of lice infestation between different age groups in schoolchildren. ${ }^{10-12,15}$ However, in the present study there was no significant relation between infestation rate and girls' age or class level.

The hair characters and their effect on the rate of infestation of pediculosis are highly controversial.10In this study, there was no significant effect of hair characters (color, length, type and kind) on lice infestation. This was in accordance with some studies which reported that hair length did not appear to be an independent risk factor. ${ }^{11}$ However, other studies found that long-haired girls were more infested with lice. ${ }^{6,10,15,12}$ The findings can be attributed to the fact that the hair characters in Albaha population are similar.

The present study showed that the frequency of hair washing significantly affected lice infestation, $(\mathrm{P} \leq 0.001)$. Similar results were found in several studies, while other authors showed contradictory results. ${ }^{11,12,18,19,28,29}$ Girls whose mothers washed their hair were less infested than those who washed their own hair. To the best of our knowledge, it is the first time the effect of such a factor on the prevalence of pediculosis is investigated.

Head lice infestation was significantly higher $(\mathrm{P} \leq 0.001)$ in girls sharing combs and towels in this study. This is consistent with some researches. ${ }^{11,12,18,30}$ However. Blow- drying hair after washing was found to be an important factor in preventing pediculosis in this research; $(\mathrm{P} \leq 0.001)$. This may be due to the lethal and detaining effect of heat on adults and eggs/nits, as well as considerably reducing optimum humidity.

Crowdness is another factor that affects the prevalence of lice infestation. In this study the highest infestation was found in heavily crowded classrooms (89.52\%). Girls who shared bedrooms with family members were recorded to have a higher rate of infestation $(\mathrm{P} \leq 0.05)$. Similar results were reported by. ${ }^{10,18}$ These findings are predictable, as crowdness increases there will be more physical contacts, especially head to head contact which are the most important factors in transmission of head lice infestation. ${ }^{30}$ However found low or no significant correlation between lice infestation and the size of family or the number of people sharing rooms. ${ }^{12,28}$

The impact of the socio-economic and education level of parents was investigated. Infestation rate was directly proportional to the father's education level, increasing with higher education $(\mathrm{P} \leq 0.01)$. This was consistent with the results of, while it differed with. ${ }^{11,12}$

\section{CONCLUSION}

Family education is needed to implement proper personal hygiene practices and cease sharing personal items. Periodic screening of students at school and home is recommended for early detection and treatment.

The results recorded in this research also indicated that there was no significant relationship between lice infestation and mother's occupation, family income, number of family members, girls' order amongst siblings, and the presence or lack of a house servant.

Funding: The research was funded by the University of Albaha - Deanship of Scientific Research

Conflict of interest: None declared

Ethical approval: The study was approved by the institutional ethics committee

\section{REFERENCES}

1. Elston DM. What's eating you? Pediculus humans (head louse and body louse). Cutis. 1999;63:259-46.

2. Chesney PJ, Burgess IF. Lice: resistance and treatment. Contemp pediatr. 1998;15:181-92.

3. Counahan ML, Andrews RM, Weld H, Helen, Speare R. What parents in Australia know and do about head lice. Rural Remote Health. 2007;7(3):687.

4. Burkhart CN, Burkhart CG. Fomite transmission in head lice. J Am Acad Dermatol. 2007;56(6):1044-7.

5. Koch T, Brown M, selim P, Isam C. Towards the eradication of head lice: literature review and research agenda. J Clin Nursing. 2001;10:364-71. 
6. AL-Shawa RM. Pediculosis capitis, infestation according to sex and social factors in Gaza Governorate. The Islamic University Journal. 2008;16(1):75-83.

7. El-Mehmady RM. The prevalence of the head lice Pediculus humanus capitis. J Egypt Ger Soc Zool. 1995;16(E):113-24.

8. Bahamdan K, Mahfour AA, Tallab T. Skin diseases among adolescent in Albaha, Saudi Arabia. Int J Dermatol. 1996;35:405-8.

9. Hodjati MH, Mousavi NM, Mousavi M. Head lice infestation in school children of a low socioeconomic area of Tabriz city, Iran. African Journal of Biotechnology. 2008;7(13):2292-4.

10. Mahmood S. Head pediculosis among in Baghdad area elementary school children. Iraqi Journal of Science. 2010;51(1):49-55.

11. Vahabi B, Vahabi A, Gharib A, Sayyadi M, Sayyad $\mathrm{S}$. Prevalence of head louse infestations and factors affecting the rate of infestation among primary. Life Sci J. 2013;10(12s):360-4.

12. AL-Megrin WE. Assessment of the prevalence. Pediculosis capitis among primary school girls in Riyadh, Saudi Arabia. Research Journal of Environmental Sciences. 2015;9:193-9.

13. Boley S, Brennan B, Foster E, Goldberg J, Harrison $\mathrm{R}$, Heringhausen $\mathrm{J}$, et al. A comprehensive guide to identify, treat, manage, and prevent head lice. Michigan Head Lice Manual. 2013;P37.

14. Al- Saeed WY, Al-Dawood KM, Bukhari IA, Bahnassy AA. Prevalence and pattern of skin disorders among female school children in Eastern Saudi Arabia. Saudi Med J. 2006;27:227-34.

15. Bosely HA, El-Alfy NM. Head lice infestations Anoplura: pediculidae in Saudi and non-Saudi school-aged children. J Egyptian Soc Parasitol. 2011;41:131-40.

16. Amin TT, Ali A, Kaliyadan F. Skin disorders among male primary school children in Al Hassa, Saudi Arabia: prevalence and socio-demographic correlates-a comparison of urban and rural populations. Rural Remote Health. 2011;11(1):1517.

17. Gulgun M, Balci E, Karaoglu A, Babacan O, Turker T. Pediculosis capitis: prevalence and its associated factors in primary school children living in rural and urban areas in Kayseri, Turkey. Cent Eur. J. Public Health. 2013;21:104-8.

18. AlBashtawy M, Hasna F. Pediculosis capitis among primary-school children in Mafraq Governorate Jordan. East Mediterr. Health J. 2012;18:43-8.
19. Moradi A, Zahirnia AH, Alipour AM, Eskandari Z. The prevalence of pediculosis capitis in primary school students in Bahar, Hamadan Province, Iran. J Res Health Sci. 2009;9:45-9.

20. Al-Maktari MT. Head louse infestations in Yemen: prevalence and risk factors determination among primary schoolchildren, Al-Mahweet Governorate, Yemen. J Egyptian Soc Parasitol. 2008;38:741-8.

21. Raheem TAA, El Sherbiny NA, Elgameel A, ElSayed GA, Moustafa N, Shahen, S. Epidemiological comparative study of pediculosiscapitis among primary school children in fayoum and minofiya governorates. Egypt J Commun Health. 2015;40(2):222-6

22. Karakus M, Arici A, Toz SO, Ozbel Y. Prevalence of head lice in two socio-economically different schools in the center of Izmir city, Turkey. Turkiye Parazitol Derg. 2014;38:32-6.

23. Mallik S, Chaudhuri RN, Biswas R, Biswas B. A study on morbidity pattern of child labourers engaged in different occupations in a slum area of Calcutta. J Indian Med Assoc. 2004;102:198-200.

24. Falagas ME, Matthaiou DK, Rafailidis PI, Panos G, Pappas G. Worldwide prevalence of head lice. Emerging Infect Dis. 2008;14:1493-4.

25. Durand R, Maillard B, Michel B, Bruel C, Bouvresse C, Izri A. Detection of pyrethroid resistance gene in head lice in schoolchildren from Bobigny France. J Med Entomol. 2011;44:796-8.

26. Burgess IF. Human lice and their management. Adv. Parasitol. 1995;36:271-342.

27. Spear R, Buettner PG. Head lice of primary school in Australia and implications for control. J. Dermatology. 1995;38:285-90 .

28. Sim S, Lee WJ, Yu JR, Lee IY, Lee SH. Risk factors associated with head louse infestation in Korea. Korean J Parasitol. 2011;49:95-8.

29. Tappeh KH, Chavshin AR, Hajipirloo HM, Khashaveh S, Hanifian H. Pediculosis capitis among primary school children and related risk factors in Urmia, the main city of West Azarbaijan, Iran. J Arthropod-Borne Dis. 2012;6:79-85.

30. Toloza A, Vassena C, Gallardo A, Audino PG, Picollo MI. Epidemiology of Pediculosis capitis in elementary schools of Buenos Aires, Argentina. Parasitol Res. 2009;104:1295-8.

Cite this article as: Gharsan FN, Abdel-Hamed NF, Elhassan SM, Gubara NR. The prevalence of infection with head lice (pediculus humanus capitis) among elementary girl students in Albaha region- Kingdom of Saudi Arabia. Int J Res Dermatol 2016;2:12-7. 